\title{
Linfossarcoma intracerebral em bovino
}

\author{
Intracerebral lymphosarcoma in a cow
}

Rafael Almeida Fighera' ${ }^{1}$ Claudio Severo Lombardo de Barros ${ }^{2}$

- RELATO DE CASO -

RESUMO

Relata-se um caso de linfossarcoma intracerebral em uma vaca holandesa de 2 anos e meio que apresentou cegueira, embotamento e anosmia por duas semanas. O soro deste bovino testou positivo para anticorpos contra o vírus da leucose bovina. Na necropsia, tumores caracterizados por massas branco-amareladas $e$ macias, foram vistos em vários órgãos, incluindo linfonodos, baço, rim, fígado, intestino e útero. No hemisfério direito do telencéfalo, havia uma massa arredondada, macia, circunscrita, branco-rósea com 5,0 $x$ $5,0 \times 4,5 \mathrm{~cm}$ envolvendo os lobos parietal, temporal $e$ occipital. Histologicamente, os múltiplos tumores tinham o mesmo aspecto e consistiam de pequenos linfócitos neoplásicos com baixa atipia e estroma escasso.

Palavras-chave: doenças de bovinos, linfossarcoma cerebral, linfoma cerebral, leucose bovina, oncologia, patologia.

\section{ABSTRACT}

A case of intracerebral lymphosarcoma is described in a 2-year-old Holstein-Friesian cow, which developed depression and anosmia for two weeks. Serological tests for bovine leukemia virus were positive. Necropsy findings included multicentric whitish yellow tumoral masses involving several organs such as superficial and internal lymphnodes, spleen, kidney, liver, intestine, and uterus. In the right telencephalic hemisphere there was a circunscribed, discrete, rounded, pink-yellowish $5.0 \times 5.0 \times 4.5 \mathrm{~cm}$ mass, which involved the parietal, temporal e occipital lobes. All the multiple tumoral masses had the same histological aspect consisting of neoplastic small lymphocytes with little atypia and scant stroma.

Key words: diseases of cattle, cerebral lymphosarcoma, cerebral lymphoma, bovine leukosis, oncology, pathology.

\section{INTRODUÇÃO}

Os tumores primários do sistema nervoso central em bovinos são raros, constituindo apenas $0,33 \%$ a $2,5 \%$ das doenças do sistema nervoso central nessa espécie (SANCHES et al., 2000). Linfossarcomas são os tumores nãoneuroectodérmicos mais comuns e ocorrem associados à leucose bovina enzoótica (LBE) multicêntrica do adulto (SUMMERS et al., 1995). Geralmente formam massas tumorais em diversos locais, inclusive no canal vertebral, comprimindo a medula espinhal e as raízes dos nervos espinhais, causando quadros clínicos de disfunção medular (REBHUN et al., 1984; SHERMAN, 1987). No entanto, raramente esses tumores são descritos com localização craniana e, nas raras descrições com essa localização, os tumores são epidurais ou subdurais, produzindo sinais encefálicos por ocupação de espaço na cavidade craniana e compressão do encéfalo (SMITHY \& ANDERSON, 1977; SWEENEY et al., 1986; SHERMAN, 1987). Descreve-se aqui um caso de linfossarcoma no cérebro de um bovino como parte do quadro de LBE multicêntrica do adulto.

\section{RELATO DO CASO}

Uma vaca holandesa de 2 anos e meio foi submetida à eutanásia por apresentar cegueira, embotamento e anosmia por duas semanas. O soro deste bovino havia sido testado com resultado positivo

\footnotetext{
${ }^{1}$ Médico Veterinário, Aluno de Mestrado do Programa de Pós-graduação em Medicina Veterinária, Área de Concentração em Patologia Veterinária, Universidade Federal de Santa Maria (UFSM), 97105-900, Santa Maria, RS. E-mail: anemiaveterinaria@bol.com.br. Autor para correspondência.

${ }^{2}$ Médico Veterinário, PhD., Professor Titular do Departamento de Patologia, UFSM.
} 
para anticorpos contra o vírus da leucose bovina (BLV). Na necropsia, tumores caracterizados por massas branco-amareladas e macias foram vistos em vários órgãos, incluindo linfonodos, baço, rim, fígado, intestino e útero. Acentuada assimetria era observada nos hemisférios telencefálicos; o hemisfério direito estava volumoso, mostrava aderência da dura-máter às leptomeninges e havia conificação do cerebelo. $\mathrm{Na}$ superfície de corte transversal desse hemisfério, havia uma massa arredondada, macia, circunscrita, brancorósea com 5,0 × 5,0 × 4,5cm envolvendo os lobos parietal, temporal e occipital. Essa massa comprimia as estruturas encefálicas adjacentes (Figura 1). No exame histológico, os múltiplos tumores consistiam de um manto de pequenas células com citoplasma escasso e núcleos levemente pleomórficos. No cérebro, esses pequenos linfócitos não-clivados formavam tapetes separados por finas trabéculas de tecido conjuntivo. Além disso, linfócitos neoplásicos não-clivados eram vistos no espaço de Virchow-Robin, formando manguitos perivasculares neoplásicos.

\section{DISCUSSÃO}

Os linfossarcomas de bovinos podem ocorrer de forma esporádica, não-associada à infecção viral, ou de forma enzoótica, associada à infecção pelo BLV (VALLI, 1993). O linfossarcoma bovino esporádico ocorre de forma multicêntrica em bezerros (um a seis meses de idade), no timo de animais jovens (seis a 30 meses de idade) ou sob a forma de nodulações cutâneas (um a três anos de idade). Na forma enzoótica, o BLV provoca a transformação de linfócitos B; a proliferação desses linfócitos transformados produz massas tumorais sólidas (linfossarcomas) nas mais diversas localizações anatômicas (distribuição multicêntrica) em cerca de $1 \%$ a $5 \%$ dos bovinos infectados (JACOBS et al., 2002).

Os principais sítios de localização dos tumores na LBE multicêntrica do adulto são linfonodos, coração (primariamente átrio direito), abomaso, útero, intestino delgado, canal vertebral e vários outros locais. No canal vertebral, esses tumores produzem alterações compressivas da medula espinhal, que causam sinais clínicos relacionados (VALLI, 1993). Embora a localização intracraniana dos linfossarcomas em bovinos não seja desconhecida, é incomum (SUMMERS et al., 1995). Além disso, não se conhecem documentações de casos em que o tumor tivesse localização intracerebral, como é descrito aqui.

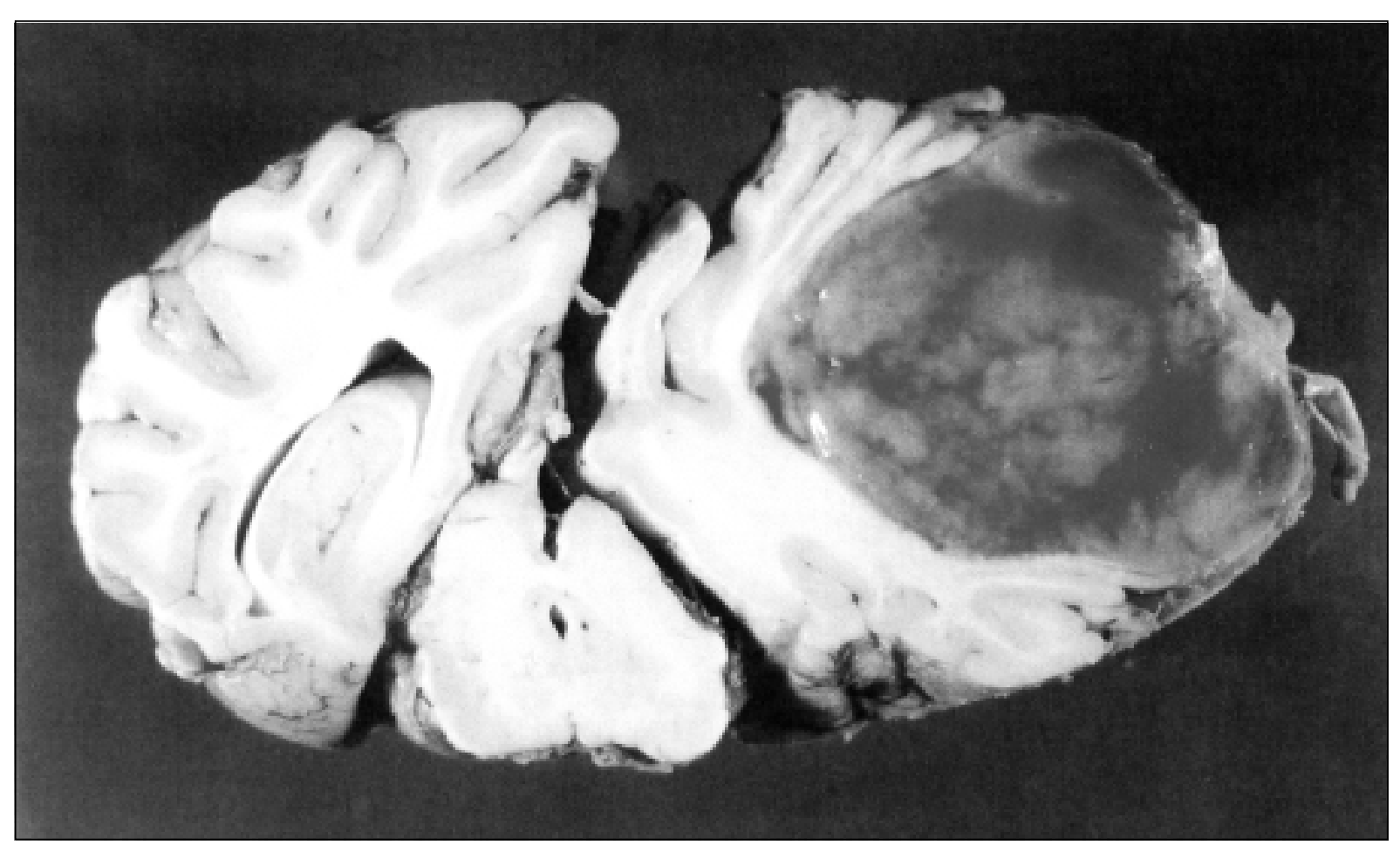

Figura 1 - Bovino, encéfalo, superfície de corte, linfossarcoma. No hemisfério direito do telencéfalo há uma massa arredondada, circunscrita, branco-rósea. Observe que o tumor comprime acentuadamente os colículos mesencefálicos.

Ciência Rural, v.34, n.3, mai-jun, 2004. 
Os linfossarcomas cerebrais são relatados em cães (PFAFF et al., 2000; LONG et al., 2001), gatos (FONDEVILA et al., 1998), eqüinos (KANNEGIETER \& ALLEY, 1987), macacos (KAHNT et al., 2002) e em pessoas (GIROLAMI et al., 2000). Na maioria dos casos, esses tumores são considerados como metástases, mas também podem ocorrer como manifestação primária. Em humanos, linfomas não-Hodgkin metastáticos afetam as áreas superficiais do cérebro, principalmente ao redor das raízes nervosas revestidas pela dura-máter; por outro lado, linfomas não-Hodgkin primários se caracterizam por afetar o parênquima cerebral, ou seja, são na maioria das vezes intracerebrais (GIROLAMI et al., 2000). Embora o linfoma primário seja uma neoplasia rara em humanos, sua incidência aumenta significativamente nos pacientes imunossuprimidos, principalmente naqueles com AIDS (GIROLAMI et al., 2000). A mesma situação parece ocorrer em macacos rhesus (Macaca mulatta) infectados pelo vírus da imunodeficiência dos símios (KAHNT et al., 2002). Uma rara forma de linfossarcoma associada aos vasos sangüíneos, denominada linfossarcoma angiotrópico é descrita em humanos (GIROLAMI et al., 2000), cães (DARGENT et al., 1988; BUSH et al., 2003) e gatos (LAPOINTE et al., 1997). A metástase de linfossarcoma epiteliotrópico (micose fungóide) já foi descrita no cérebro de um cão (CZASCH et al., 2000).

A compressão e destruição do tecido cerebral causadas pela massa tumoral e pelo edema cerebral associado, foram responsáveis pelos sinais clínicos apresentados por este bovino. A neoplasia desse relato foi interpretada como parte de um linfossarcoma multicêntrico. As evidências para isso foram a distribuição característica do tumor nos diversos órgãos e o aspecto histológico das lesões.

\section{REFERÊNCIAS BIBLIOGRÁFICAS}

BUSH, W.W. et al. Intravascular lymphoma involving the central and peripheral nervous systems in a dog. J Am Anim Hosp Assoc, v.39, p.90-96, 2003.

CZASCH, S.; RISSE, K.; BAUMGARTNER, W. Central nervous system metastasis of a cutaneus epitheliotropic lymphosarcoma in a dog. J Comp Pathol, v.123, p.59-63, 2000.

DARGENT, F.J.; FOX, L.E.; ANDERSON, W.I Neoplastic angioendotheliomatosis in a dog: an angiotropic lymphoma. Cornell Vet, v.78, p.253-262, 1988 .

FONDEVILA, D.; VILAFRANCA, M.; PUMAROLA, M. Primary central nervous system T-cell lymphoma in a cat. Vet Pathol, v.35, p.550-553, 1998 .

GIROLAMI, U.; ANTHONY, D.C.; FROSCH, M.P. O sistema nervoso central. In: CONTRAN, R.S.; KUMAR, V.; COLLINS, T. Robbins - Patologia estrutural e funcional. 6.ed. Rio de Janeiro : Guanabara Koogan, 2000. 1251p. Cap.30, p.11531211

JACOBS, R.M.; MESSICK, J.B.; VALLI, V.E.O. Tumors of the hematopoietic system. In: MEUTEN, D.J. Tumor in domestic animals. 4.ed. Iowa : Iowa State, 2002. 788p. Cap.3, p.119-198.

KAHNT, K. et al. SIV-associated lymphomas in rhesus monkeys (Macaca mulatta) in comparison to HIV-associated lymphomas. Vet Pathol, v.39, p.42-55, 2002.

KANNEGiETER, N.J.; ALlEy, M.R. Ataxia due to lymphosarcoma in a young horse. Aust Vet J, v.64, p.377-379, 1987.

LAPOINTE, J.M.; HIGGINS, R.J.; KORTZ, G.D. Intravascular malignant T-cell lymphoma (malignant angioendotheliomatosis) in a cat. Vet Pathol, v.34, p.247-250, 1997.

LONG, S.N.; JOHNSTON, P.E.; ANDERSON, T.J. Primary Tcell lymphoma of the central nervous system in a dog. J Am Vet Med Assoc, v.218, p.719-722, 2001.

PFAFF, A.M.; MARCH, P.A.; FISHMAN, C. Acute bilateral trigeminal neuropathy associated with nervous system lymphosarcoma in a dog. J Am Anim Hosp Assoc, v.36, p.57$61,2000$.

REBHUN, W.C. et al. Compressive neoplasms affectingh the bovine spinal cord. Comp Cont Educ Pract Vet, v.6, p.396440, 1984.

SANCHES, A.W.D. et al. Doenças do sistema nervoso central em bovinos no sul do Brasil. Pesq Vet Bras, v.20, p.113-118, 2000.

SHERMAN, D.M. Localized diseases of the bovine brain and spinal cord. Vet Clin North Am Food Anim Pract, v.3, p.179191, 1987.

SMITH, B.P.; ANDERSON, M. Lymphosarcoma of the brain in a Holstein bull. J Am Vet Med Assoc, v.130, p.333, 1977.

SWEENEY, R.W. et al. Intracranial lymphosarcoma in a Holstein bull. J Am Vet Med Assoc, v.189, p.555-556, 1986.

SUMMERS, B.A.; CUMMINGS, J.F.; DE LAHUNTA, A. Veterinary neuropathology. Baltimore : Mosby, 1995. 527p.

VALLI, V.E.O. The hematopoietic system. In: JUBB, K.V.F., KENNEDY, P.C., PALMER, N. Pathology of domestic animals. 4.ed. San Diego : Academic, 1993. 653p. V.3, Cap.2, p.101265 . 